\title{
Shoring and Resilience: The Resilience Process of Mothers of Premature Children
}

\author{
Ndje Ndje Mireille ${ }^{1 *}$, Konfo Tcholong Clémence Idriss ${ }^{2}$ and Tsala Tsala Jacques-Philippe ${ }^{3}$ \\ ${ }^{1}$ Senior Lecturer in Clinical and Pathological Psychology, Department of Psychology, University of Yaounde 1, Cameroon \\ ${ }^{2}$ PhD student in Clinical and Pathological Psychology, Department of Psychology, University of Yaounde 1, Cameroon \\ ${ }^{3}$ Head of Department, Full Professor in Clinical and Pathological Psychology, Department of Psychology, University of Yaounde 1, Cameroon
}

Submission: August 10, 2020; Published: September 25, 2020

*Corresponding author: Ndje Ndje Mireille, Senior Lecturer in Clinical and Pathological Psychology, Department of Psychology, Faculty of Art, Letters and Human Science, University of Yaounde 1, Cameroon

\begin{abstract}
Premature delivery as a life event disrupts the mother's psyche like a tidal wave. This birth is registered in this organization as a real trauma because by the drive overflow which is inherent to it and the influx of external excitations which will exceed the capacity of the psychic apparatus, prematurity has a traumatic value. Faced with this extraordinary birth, many mothers get bogged down in psychological suffering while others manage to overcome it. Thus, we question the resilience trajectory of mothers of premature children. This is in order to understand the processes that underlie this trajectory. To achieve this, we made use of the clinical method which offers us the possibility of accessing the subject's singularity and, in turn, the psychic processes implemented in this situation. Semi-structured interviews were conducted with four women who gave birth prematurely. They were met at the Gyneco-Obstetric and Pediatric Hospital in Yaounde where their children were hospitalized. The interview corpus has been analyzed through content analysis. The findings show that resilience in these mothers is subtended by a process of multiple shoring which on the one hand reduces risk factors and on the other hand mobilizes and activates protective factors.
\end{abstract}

Keywords: Shoring up; Resilience; Mother; Preterm delivery

\section{Introduction}

The gestation period of pregnancy is a period accompanied by major rearrangements. According to Zah (1988), it tests a woman's psychic organization. This period constitutes a real crisis of identity and psychological maturation, Bayle (2009). To this extent, the psychic changes that take place during this period work towards maturation through the identity and existential crisis which must lead to the acquisition of maternal identity.

For Emselem, Ciccone, Berber \& Mellier [1], the birth of a child is a major event with very strong emotional potential. Thus, each birth is an expected and prepared event throughout the pregnancy. It may happen that during this waiting that the child is born earlier or even too early; that is, before the end of pregnancy. This birth before the term would come like a tidal wave to set in motion all the representations of the mother. The trauma of this unexpected and perilous birth, the brutal, destabilizing and sometimes very painful event leads to a break in the maternal psyche already weakened by motherhood. This is because the conditions of birth generate a "drive overflow" which is comparable to a "traumatic upheaval" because the "external excitations" which flow will "exceed the capacities of capacity of the psychic apparatus" of the parent [2].

This birth according to Freud [3] constitutes a violent shock affecting the mother who did not expect it and is experienced as a trauma which can disrupt the psychic functioning of the parents [4]. Thus, the mother's psychic apparatus is overwhelmed by too much excitement and collapses, while becoming disorganized [3]. This corresponds to what Marty [5] described as excesses. Indeed, for him, the trauma would be an excess of stimulation, of image, an absence of sense, an excess of anxiety, an overflow of capacities of capacity etc. The mother's psyche following a premature birth thus faces an overflow of her defenses due to numerous violent excitations which gradually disorganizes her. As faced with this extraordinary birth and the psychological trauma that it induces, many mothers get bogged down in mental suffering while others manage to maintain stable operation. This demonstrates their capacity for resilience, that is, in the latter, there is a developmental recovery following the confrontation with the trauma. 
Registering in one hand of the life trajectory perspective which stipulates that: life takes place in time and space, lives are interconnected, life is influenced by the free will of mankind and events are recorded over time [6,7]. This offers the possibility of situating individual experiences in a socio-historical perspective which highlights the central place of the contribution of the environments in the trajectories of individuals [8]. And on the other hand in the psychoanalytic perspective of Lighezzolo \& Tychey (2004) who consider that the construction of resilience is at the interface between the intrapsychic functioning of the subject and its environmental reality, with the inter-subjective spaces it mobilizes. We have set out to investigate the psychic processes that underlie the resilience trajectory of mothers of premature children.

\section{Background}

Birth is usually a happy, expected and prepared event throughout pregnancy. But it can happen that during this waiting, the child is born earlier or even too early than expected. That is to say before the end of pregnancy. Premature delivery is therefore a sudden and unforeseen situation and the premature child comes to upset the representation of childbirth, even that of the baby that the parents built during the gestation period. By approaching the question of premature births, the majority of works anchored in the psychoanalytic approach recognizes these births as being traumatic for parents in general and the mother in particular. This is because confronting the baby who arrived too early generates anxiety among parents. The mother, as pointed out by Vollenweider, Nicastro, Sabeh, Lambiel, and Pala (2004) must accept the abrupt separation from her child which can be a source of frustration for her; beyond this frustration, there would be a great disappointment not to have had "a perfect baby" in "perfect conditions". The resulting disappointment is often mixed with a feeling of helplessness.

According to Herzog et al. [2] the conditions of birth generate a "drive overflow" which is comparable to a "traumatic upheaval" because the "external excitations" which flow will "exceed the capacities of capacity of the parent's psychic apparatus. Premature birth is thus experienced as a trauma that can disrupt the parents' psychic functioning [4]. Indeed, the eruption of reality caused by premature birth inscribed according to Ansermet (1999 p.43) in the trauma clinic which "leads to a symbolic abolition which leaves without representations. [...] It's this hole that creates trauma." Starting from the definition of psychic trauma, preterm delivery is traumatic in that there is an unexpected, sudden and too early delivery that reaches the unprepared and vulnerable maternal psyche. Generating fear and temporality is thus modified and the mother would no longer be able to register in a historical continuity where the present is woven from impressions left in the past and projections into the future, Bréhat (2018).

\section{Methodology}

According to the objective of this study which is the apprehension of the psychic processes that underlie the trajectory of resilience of the mothers of premature children, we appealed to the clinical method which is fundamentally qualitative and is based on the study of cases. This choice is justified by the fact that she is interested in the singularity of the case, this to make a deep understanding of the latter. Because we seek in this study to understand the psychic processes underway in the resilience process of these mothers, the use of this method is relevant. To do this, four mothers who gave birth prematurely were selected based on the inclusion criteria. They then presented a developmental recovery after childbirth and were 17 years old for the youngest and 29 years old for the oldest. We attribute them pseudonyms as; Danielle, Ismaela, Dalia and Éléonore. They were met at the Gynecological, Obstetric and Pediatric Hospital of Yaounde which is a benchmark hospital structure in Cameroon. The participants' consent regarding this registration was obtained; by doing so, we respected the ethical principle of research which stipulates that the researcher must obtain the participant's consent for all the actions he will have to take in the context of the research. At the start of the interviews, we explained the purpose of our research to the participants without mentioning our working hypothesis. This is to avoid bias in the responses. The data were collected through semi-structured interviews which consist of words from mothers on their general experiences and particularly their experiences of pregnancy, premature delivery and its aftermath. The interviews lasted for an average of 45 minutes each and were recorded using a voice recorder after the participants' consent. The data collected was transcribed and analyzed with the technique of thematic content analysis.

\section{Findings}

The analysis we carried out retrieved the following themes: the experience of psychic disorganization and adversity following premature delivery, the turning point, the processes put in place to modify the trajectory.

\section{The experience of psychic disorganization and adversity following premature delivery}

The experience of psychic disorganization and adversity following premature delivery in trajectory of resilience implies evoking adversity $[8,9]$. In this sense, prematurity and its aftermath are adversities faced by mothers. Indeed, this situation exposes mothers to other adversities such as the state of health of the child who must be admitted in the intensive care unit, cessation of professional activities, constraints relating to hospitalization of the child. Thus, in this study, following Noltemeyer \& Bush [10] Riley \& Masten [11], by adversity, they designated the experiential experience, the painful feeling, the suffering or the difficulty experienced by the mother in the face 
of premature birth which is a stressful event and constitutes a threat to psychic integrity or to biopsychosocial homeostasis. The premature delivery had a disorganizing impact on the psyche of the participants in this study. In fact, with regard to childbirth, all the participants mentioned the sudden nature which violates their psyche like a traumatic event. It is sudden, comes too early and reaches the unprepared maternal psyche. Speaking to her, Danielle uses these words: "It just happened, it started suddenly, and the noh contractions started on Friday, August 30 just like that, I find myself there because I was not hospitalized". At the announcement of childbirth, she was invaded by numerous stimuli which she could not control.

This childbirth bursts into her existence and sets in motion her psyche as she says: When the gynecologist told me that I have to give birth, I was hot, I had tears in my eyes, I cried hot tears, I was lying on the stretcher in the hospital. He said there is nothing to do, the membrane is broken I have to give birth and what I had, you see, I never imagined, we weren't even expecting. Because I knew in such a month, I will give birth, then you are suddenly told that today you must give birth and in the shortest possible time. I was out of my mind, I was not [...] I was in a state; I was completely overwhelmed by this surprise birth. I never imagined, it was an unknown world for me, I did not know, I was absolutely not ready to give birth, I was overwhelmed. For Ismaela, Due to the fact that she started monitoring her pregnancy very early and that it was going on normally, premature birth came as a real test of reality, over passing all that she had undertaken so that the pregnancy goes to its term: So I couldn't even imagine that it could happen to me one day, because of this pregnancy, I went to the hospital for a month, I followed all that I was normally asked, I did not have any problem. In my head, I was calm, I knew that I will give birth in the right conditions, unfortunately it happened as it happened, but when it happened like that, it did not stress me too much because I always had the firm condition that if the baby there cries, and they brought the baby to the incubator, she will live why, because my mother gave birth to me in the village and my brother at 6 months without an incubator, we survived.

While for Éléonore, this childbirth thus led to a drive overflow, which in turn rippled an influx of excitations which overflowed her capacity for containment: "It was a shock, huh! How did you give birth at thirty weeks? It's weird noh when you're not full term, it's weird, I felt a shock now, despite that I'm still alive noh, that of my baby too. " In her words, the interrogation associated with the oddity thus accounts for the feeling of strangeness in the face of this birth which comes to set in motion in her psyche. Psychic disorganization following premature delivery is also manifested in Éléonore's words through the succession of unfinished sentences, thus accounting for her inability to put words into her feelings: “It makes me, it's never, nor in, I don't know how to explain that to you. I never, for me, it is strange I could not imagine that one day my first pregnancy, I could go there. So, it's already almost a month outside. So, you can see it's a bit traumatic. “

For Danielle, the experience of the child's hospitalization is marked by constant activity and absence of rest, which is a source of stress for her. According to her, this stress is the cause of underproduction of milk. It's only because there I came out of an operation to directly take care of the baby. I haven't had a rest [...], we don't rest. We're always working on kids all the time, it's stressful. We have to manage the stress and it has already led to the milk underproduction. The milk itself is no longer flowing so there I manage the stress of the milk because we give the child's milk $25 \mathrm{cc}$, it must feed the child at $25 \mathrm{cc}$, I cannot produce the $25 \mathrm{cc}$ and there, my daughter is found eating $14 \mathrm{cc} 15 \mathrm{cc}$. First of all, it stresses me that the child cannot eat the quantity that is necessary, the quantity that her stomach demands.

For Ismaela, the experience of the child's hospitalization situation is also marked by stressful situations not conducive in the living conditions at the hospital and the child's situation but rather in relation to her spouse: " $\mathrm{C}$ 'is because of stress and I like to cry. When something gets beyond me, I start to cry, it's just crying. Even so far, even yesterday, he scandalized me, it's because I was same yesterday, it even stressed me out and after that I started to cry." To address the question of the experience of her child's hospitalization situation, she mentions the difficulties she encounters on a daily basis since her arrival at the hospital. Besides that, she mentioned the relationship with the nurses as well as the gap between the traditional care of premature babies and the practices taking place in the hospital.

So, when I got there, it was not easy with the nurses, because I didn't know anything, it's true that the way my mother treated my nephews in the village, it's not the same way here. Here, you must, we must teach you how you must feed the child how, how. And when you arrive that you do not know, well it's true that there are teams and teams. There are certain teams here there that you even go to them because you do not know how to do it and inquire, they start insulting you, they tell you anything, it is not easy. Still with regard to hospitalization, Dalia expresses very little of her experiences and she is just content to speak of the financial blow of this hospitalization: "Here it is a bit complicated, there are many prescriptions that we are given, they put a lot of pressure on us to pay the money, they don't want us to wait with the cash. We don't want to agree to give the cash bill at once till the child has finished with the follow-up first, we don't want to do that. They are also mounting pressure, but we also say that we must give small, small like that so that the bill does not weigh at the end. It goes well. My mother comes here, my mother-in-law too, and my husband also comes to visit me.

\section{The turning points}

The turning point is considered to be the main point in the recovery, Richardson [12]. Speaking of the turning point, Rutter 
[13] mentioned that it is a heterogeneous set of lasting changes in psychological functioning following an ordeal or significant experience in a person's life. For mothers facing preterm delivery, the turning point is the actual coming into contact with the child. Indeed, the coming into contact with the child and the subsequent investment reverses the curve and induces a process of resilience in these mothers. Participant Danielle puts it this way; my daughter is a source of gratification for the fact that she was born from a twin pregnancy, even though the other baby died. Regarding the investment, there is an idealization of her baby: "When I am with my child, I am very proud, to have had my twin because in any case, even if his sister did not stay, she remains a twin, she remains my daughter she is indeed, she lived for me, she is, despite its complications because she also came out very tired". These words of Danielle highlight the fact that her daughter, despite this delivery and the loss of the other child, is invested as a "narcissistic gratification"; it is the support for the care of maternal narcissism undermined by prematurity.

The baby's state of health and the pride at the sight of her daughter make her feel mom and therefore her maternal identity is consolidated: "You see noh, really I am proud when I see my daughter, I am proud of her, I am, I am. I feel like a mom, I feel proud I have all felt what a mom can feel when her daughter is as healthy as she is currently." For Ismaela, the turning point is the reminder of her experience of prematurity. Drawing from her experience as premature child and that of her nephews permitted her to find the strength necessary to cope with this child. This experience was also the turning point for her: I went out from noon to $5 \mathrm{pm}$, I was outside. It is when I leave to sit outside that I also started to think, I ask myself the questions, this is where I remember that I myself was first premature, my nephews, here I am today 'hui!. They didn't put me in the incubator, the other same thing that means this one too, I only need to apply myself and also give my love and the rest when I came home. As for Dalia, with the daily confrontation of her child to whom she provides care, she expresses emotions such as joy and she identifies with maternal roles: "When I carry my child, she makes me happy at heart, how good it is that God gave me the child. I am very proud. I already see myself as a mother too, as a mother too.

It is also the case of Éléonore who evokes feelings sustained and nourished by the admiration of the baby who comes like a sort of mirror to show Éléonore the reflection of her motherhood and catalyzes the identification with the maternal role: Whenever we look at each other, I feel like I am her mom, I realize that she is really my daughter and at the same time, I feel that she needs me and I felt it and realize that I am her mom. And every time I wear it, even though she is still small, she is happy. Whenever we look at each other, there is something that is very strong between her and me, and these moments make me realize that she is my daughter.

\section{The processes implemented to modify the trajectory}

The processes thus mentioned constitute anchor points for the reversal of the developmental trajectory. For mothers of premature babies, they are mainly the process of multiple shoring up and making sense of the situation. Faced with the adversity induced by prematurity and its aftermath, to reverse the developmental trajectory, work will begin on the premature birth and its aftermath. It is mainly based on symbolization which, although all the attempts at making sense are not satisfactory, it is found in a quest for meaning. In addition to this work of symbolization, we note the use of defense mechanisms such as intellectualization, the setting aside of affects, the idealization of one's baby to face adversity. These psychic processes take place in a container called shoring. Indeed, they rely on the one hand on the group of "premature mothers", the medical profession and especially their family which gives them financial and moral support. This is how Danielle, regarding the shoring evokes: The family anyway, the majority supported me. Really, without this support, I don't think I would have gotten out of this gynecological bill because the bills were enormous. At first it was mine, as I underwent the cesarean and its came twin, without counting the kits and the tests, to do everything and then come back to the children, the family helped me a lot.

With regard to Ismaela and shoring up on the medical team or the peer group, her stay in the hospital although being in an extraordinary situation was beneficial to her insofar as she $s$ 'expresses as follows: I already know a lot. First, to take good care of the child, secondly, a lot of little things, maybe the way we should feed the child, the way we should make the child sleep, the way we should wake up the child. Before I thought I should only wash and breastfeed the child. This birth gave me a lot of training, I learned a lot on this child. Within this hospital structure, in particular in the neonatal service where we collected the data, the nursing staff takes care only of the health aspect, they are not responsible for care such as washing, feeding, etc. It thus constitutes for these mothers props of shoring on which they learn to come into contact with their baby. These staff also constitute for them maternal figures who participate in their support with regard to becoming a mother.

Regarding the peer group (other women who gave birth prematurely), at the Gynecological Obstetric and Pediatric Hospital of Yaoundé (HGOPY), these mothers are housed in a hospital room, which allows them to be closer to their children, in addition to that, being in their twenties or even more in the same situation constitutes for these mothers the bases on which they rely to overcome the painful emotions and emotions inherent in this situation. Because of its functioning, this group is similar to African communities where the individual is not alone in going through the situation he faces. The group thus allows in the sense of Sow [14] to resume violence or pain in our case. Indeed, when one of these mothers found herself in a situation that inflicts pain on what they are going through, the whole group tightens around them to play the role of container. 


\section{Psychology and Behavioral Science International Journal}

\section{Discussion of Findings}

For Freud [15], shoring is a remedy or a way out of a crisis that the subject uses to overcome difficulties that are difficult to overcome. To cope with prematurity, mothers find remedies to get out of this crisis. Shoring is thus the main remedy as mentioned by Chassaing [16]. According to him, man naturally depends on three registers (impulses, civilizations and propping up), and he uses the means of support which are best offered to him culturally. Because of the traumatic disorganization it creates, premature delivery is a crisis situation (abrupt and decisive change in the course of gestation) which involves a rupture of the psychic rearrangements in progress, an early separation of the mother from her baby. And a removal of the child from the mother's breast without developing the work is separation being carried out. As mentioned by Kaës [17], faced with this crisis, the mother will seek support, find reinforcement and comfort due to the fact that, through deregulation, is born the dynamic creation of new regulations. For Kaës [17], shoring is thus the central mechanism in the process of overcoming the crisis or resilience. Shoring is a support which allows the mother to bounce back and find the psychic balance broken by prematurity. In this crisis, there is a considerable gap between physical birth and psychic birth. Childbirth bursts into the psyche and the mother becomes a prey to many sources of vulnerabilities, faced with this break-in. The shaken maternal psyche mobilizes resources and defenses so as not to collapse. This psychic reorganization is in the sense of Kaës [17] a multi-supported training. To recover and not to collapse (psychic collapse) and get bogged down in mental trauma and or maternal difficulty, the "premature mother" relies on the one hand of the peer group, which in this case constitutes a true community and works for the collective resumption of the violence induced by this childbirth and its aftermath, other parts on itself and the medical profession. This allows him to control the painful effects induced by prematurity. The new regulation necessary to restore psychic balance is put in place by shoring.

Following the logic of multiple shoring advocated by Kaës [17],) which stipulates that all psychic trainings are multi-shored and the remarkable qualitative variations in this training arise when certain shoring is lacking. Faced with prematurity, the mother will resort to several sources of support. It is steeped in a culture which, according to Moro (1994), by virtue of its systematic support function, contributes to the construction of the intrapsychic functioning of the individual. The mother of a premature newborn will rely on the peer group, the medical profession and herself to overcome the crisis.

In this situation, the mother relies on the peer group which constitutes for her a solid base for overcoming the effects and painful emotions. Because of its functioning, this group is similar to African communities where the individual is not alone in going through the situation she faces. The group thus allows in the sense of Sow [14] to resume violence or pain in our case. According to Kaës [17], the group as a whole, endowed with its own psychic formations and processes, irreducible to its constituent elements, is associated with the group psychic apparatus which is an apparatus of formation, transformation and connection of reality and psychic between the "premature mothers" constituting it. In this premature situation, this device produces, contains, binds, transforms and processes psychic reality. Thus, faced with the crisis situation, fitting work is carried out with the aim of binding mothers in the sense of Kaës [17], in the flawless unity of an "esprit de corps". The representations formed and the affects related to them, found the feeling of belonging, identity and the reciprocal identifications between them and their cohesion.

The shoring on the medical profession refers to the dimension of the link in the shoring. We are talking about the career-motherbaby triad. In this triad, the mother relies on the caregivers who play the role of the elders or mother or maternal figures who participate in their support. Because the first links with the premature newborns are imbued with the experience of loss, the mothers rely on the caregivers who therefore constitute, containing maternal figures who associated with the peer group, constitutes a veritable " network of 'support' on which they rely to deal with prematurity. For Kaës [17], shoring has three functions: support, modeling and recovery. For mothers of premature newborns, the peer group is used to support them in giving meaning, mastering effects and coping with the psychic disorganization induced by premature birth. The group of nurses serve as a reference model on which they rely to identify with the maternal role. The shoring finally serves as a recovery support to the extent that it allows a way out of the crisis. Shoring is indeed the container in which the processes of symbolization, mentalization and psychic elaboration will take place. In other words, by shoring up, the mother will find the resources necessary to symbolize, mentalize or elaborate the crisis (prematurity) with which she is confronted.

The symbolization allows "premature mothers" to endure the anxieties linked to various intrapsychic movements. The work of putting premature birth into meaning, by linking the various representations, allows better tolerance to the effects and decreases its intensity. The experience of prematurity cannot be fully grasped straight away during the period of its recording. There is the time it takes place as well as the time of the experience, the time where it is seized and the time when it represents itself. Thus, the meaning of this experience is gotten afterwards in a revival, a re-capture and representation; this is because special conditions are necessary for this resumption to take place [18]. As mentioned by Roussillon [18] premature delivery mobilizes unconscious aspects of psychic life which are particularly invested, potentially traumatic or overflowing with the capacities of sense at once. The participants contented themselves with a sufficient helping hand of these aspects. Later, during the hospitalization, which is a more secure and symbolic situation, the work of direction is carried out. 
This is what happens in situations where the traumatic character is sensitive and also when emotion exceeds the usual threshold, or when the psyche presents itself with the data of a situation presenting new or unexpected aspects.

Putting in place or symbolizing premature birth is therefore a work of transformation which requires the presence of an object and several times: an intersubjective time (shoring on the group), an intersubjective treatment or game (shoring on the caregivers), a self-subjective time, a time of solitary play, a narcissistic time and the dream [18]. The work of symbolizing premature birth will form the bases of the mentalization process which offers "premature mothers" possibilities for the flow and discharge of the feelings and excitations felt. They therefore have the capacity to transform lived experiences (premature birth and its aftermath) into representations, by translating their desires, needs, frustrations and psychological conflicts to the mental level. In this perspective, mentalization is the mode of psychic elaboration which makes it possible to give a complete psychic expression (affect and representation) to the drive. Mentalization calls upon psychic representations and the symbolization of effects which allows us to put into thought the excitations resulting from prematurity. In other words, with symbolization-mentalization it is a question of giving meaning to the crisis (prematurity).

By relying on multiple shoring, the psychic elaboration of prematurity will lead to a mastery of anxieties and violence relating to prematurity to give it meaning. This through symbolization, then mentalization which constitutes the processes of the initial intrapsychic which underpins the resilience of mothers following prematurity. These mothers thus have the capacity to succeed in living and developing positively, in a socially acceptable manner, despite the stress or adversity caused by premature birth [9]. This extraordinary birth has a disorganizing power to mother's psyche like a trauma. In other words, it is a psychic shock exerted by external psychic agents on the psyche causing psychic disorders there [19]. They thus come out of prematurity victoriously with renewed strength [20].

\section{Conclusion}

The objective of this article is to understand the psychic processes that underlie resilience in mothers of premature children. To do this, we used a qualitative estimate and the data were collected from four mothers who gave birth prematurely and with a resilient trajectory. The data collection was done through an interview guide that discussed the impact of preterm delivery, the adversity of it and the process of resilience. This data thus collected was the subject of a thematic content analysis. The findings obtained show that prematurity due to its traumatic nature that disrupts the mother's psyche and the hospitalization of the child leads to numerous adversities which increase stress. But the shoring on one hand on the group of nurses and on the other hand on the group of peers constitutes with the connection with the child the turning point. From there, they will overcome the traumatic disorganization and adversity caused by premature delivery and its aftermath. Shoring is thus the catalyst for the symbolization, mentalization and defense mechanisms essential to the development of resilience.

\section{References}

1. Ensellem C, Ciccone A, Berger M, Mellier D (1997) Plaisir et répétition du maternage et filiations. Dialogue, p. 137.

2. Herzog A, Muller Nix C, Mejia C, Ansermet F (2003) Etude clinique sur le rôle paternel lors d'une naissance prématurée. Psychothérapie 23: 97-106.

3. Freud S (1920) Au-delà du principe de plaisir. PUF, Paris, France.

4. Nix CM, Guex MF, Borghini A, Pierrehumbert B, Ansermet F (2009) Prématurité, vécu parental et relations parents/enfant: Eléments cliniques et données de recherche. La psychiatrie de l'enfant 52: 423450.

5. Marty F (2001) Introduction : Traumatisme, une clinique renouvelée. In: Marty F, et al. (Eds.), Figures et traitements du traumatisme (dir) Dunod, Paris, France, pp. 1-13.

6. Bernard P (2006) Dévelopment social, parcours de vie et régimes providentiels. Communication présentée à Forum CACIS, Cantre SaintPierre, Montréal, Canada.

7. Giele JZ, Elder GH (1998) Methods of life course research: Qualitative and quantitative approaches. Sage Publications, Thousand oaks, CA, United States.

8. Lévesque S (2011) Trajectoires de résilience chez des mères adolescentes victimes de violence de la part de leur partenaire amoureux : implications théoriques et pratiques pour le domaine de la promotion de la santé (Thèse de Doctorat en santé publique) Université de Montréal, Canada.

9. Cyrulnik B (1999) La résilience: un espoir inattendu, in Souffrir mais se construire/sous la dir. de MP. Poilpot, Ramonville Saint-Agne, ERES, pp. 13-24.

10. Noltemeyer AL, Bush KR (2013) Adversity and resilience: A synthesis of international research. School Psychology International 34(5): 474487.

11. Riley JR, Masten AS (2005) Resilience in context. In: Peters DRD, Leadbeater B, McMahon RJ (Éds.), Resilience in children, families, and communities: Linking context to practice and policy Kluwer Acadernic IPlenum Publishers, New York, United States, p. 201.

12. Richardson GE (2011) The application of the meta-theory of resilience and resiliency in rehabilitation and medicine. Paper presented at the Colloque Resilience: pour voir autrement en réadaptation.

13. Rutter M (1996) Transitions and Turning Points in Developmental Psychopathology: As applied to the Age Span between Childhood and Mid-adulthood. International Journal of Behavioral Development 19(3): 603-626.

14. Sow I (1977) Psychiatrie Dynamique Africaine. Payot, Paris, Farnce.

15. Freud S (1929) Malaise dans la civilisation. Payot, Paris, France.

16. Chassaing JL (2008) Détresse, secours et étayage. La revue lacannienne $2(2): 37-44$.

17. Kaës R (1990) Introduction à l'analyse transitionnelle. In: Kaës R, Missenard A, Kaspi R, Anzieu D, Guillaumin J, et al. (Eds.), Crise, rupture et dépassement, Dunod, Paris, France, pp. 1-83. 
18. Roussillon R (1996) Le processus de symbolisation et ses étapes.

19. Crocq L (2007) Traumatismes psychiques : prise en charge psychologiques des victimes. Masson Issy-les-Moulineaux, Paris, France.
20. Anaut M (2003) La résilience. Surmonter les traumatismes. Nathan Université, Paris, France.

\section{Your next submission with Juniper Publishers will reach you the below assets}

- Quality Editorial service

- Swift Peer Review

- Reprints availability

- E-prints Service

- Manuscript Podcast for convenient understanding

- Global attainment for your research

- Manuscript accessibility in different formats

( Pdf, E-pub, Full Text, Audio)

- Unceasing customer service

Track the below URL for one-step submission https://juniperpublishers.com/online-submission.php 